\title{
Local recurrence of small cell lung cancer following radiofrequency ablation is induced by HIF-1 $\alpha$ expression in the transition zone
}

\author{
JUN WAN $^{1}$, WEI WU ${ }^{2}$ and RENQUAN ZHANG ${ }^{1}$ \\ Departments of ${ }^{1}$ Thoracic Surgery and ${ }^{2}$ Hematology, The First Affiliated Hospital of Anhui Medical University, \\ Hefei, Anhui 230022, P.R. China
}

Received September 17, 2015; Accepted December 7, 2015

DOI: $10.3892 / 0 r .2015 .4541$

\begin{abstract}
Local recurrence of lung cancer following radiofrequency ablation (RFA) treatment is common. The aims of the present study were to assess how RFA treatment affects the growth of small cell lung cancer (SCLC) micrometastases in the transition zone (TZ) surrounding the ablated region and in the reference zones (RZs) of the ablated or unablated lobes and to identify the molecular mechanism(s) of lung cancer recurrence following RFA treatment. After lung micrometastases of human SCLCs had formed, RFA treatment was applied to the right upper lobe (RUL) of the lung in nude mice. Hypoxia inducible factor (HIF)- $1 \alpha$ expression, proliferation and angiogenesis potential both in the TZ and RZ were evaluated over time. Separately, at day 1, 7 and 14 following RFA treatment, the growth of micrometastases showed an $\sim 2$-fold increase in the $\mathrm{TZ}$ compared to the $\mathrm{RZ}$ of the unablated lobe, as the right lower lobe (RLL) and the growth of micrometastases in the RZ of the RUL was also induced by RFA. In addition, accelerated tumor growth in the TZ was induced by HIF-1 $\alpha$, but was not associated with tissue angiogenesis potential. We concluded that local recurrences of SCLCs caused by overproliferation of micrometastases following RFA treatment were driven by HIF-1 $\alpha$, although angiogenesis was not the driving force in the TZ.
\end{abstract}

Correspondence to: Dr Jun Wan, Department of Thoracic Surgery, The First Affiliated Hospital of Anhui Medical University, 218 Jixi Road, Hefei, Anhui 230022, P.R. China

E-mail: junwandr@yahoo.com

Abbreviations: RFA, radiofrequency ablation; SCLC, small cell lung cancer; TZ, transition zone; RZs, reference zones; RUL, right upper lobe; HIF, hypoxia inducible factor; RLL, right lower lobe; NSCLCs, non-small cell lung cancers; SCLCs, small cell lung cancers; CZ, central necrosis zone; PRA, pneumonic replacement area; $\mathrm{DAB}$, diaminobenzidine

Key words: radiofrequency ablation, small cell lung cancers, transition zone, reference zones, tumor overproliferation

\section{Introduction}

For the treatment of lung cancer, surgical resection, consisting of a lobectomy and complete lymph node dissection, has long been considered the standard treatment for resectable tumors (1). However, it is estimated that only one-third of patients with non-small cell lung cancers (NSCLCs) are suitable candidates for curative resection (2). However, for small cell lung cancers (SCLCs), a histological subtype of lung cancers with unique biological and oncological features that differ significantly from NSCLCs, standard treatment usually consists of systemic chemotherapy and radiotherapy. Surgery in association with chemotherapy and radiotherapy is only indicated for a small subset of SCLCs presenting with limited disease progression (3). Although SCLCs are sensitive to radiotherapy and chemotherapy, patients remain in remission for a relatively short duration and the emergence of rapidly growing drug-resistant metastases are frequent in such patients. Therefore, treatments for SCLCs are more likely to incorporate multidisciplinary synthetic therapies (4).

Previous studies have indicated that human NCI-H446 SCLC cells are more sensitive to thermal treatment compared to NSCLC cells, and thermal treatment can augment the cytotoxicity of chemotherapeutic drugs (5). Radiofrequency ablation (RFA) is an example of a thermotherapy technique that is advanced, minimally invasive, and is used to treat several types of neoplasms. Its application to the treatment of lung tumors has received great interest (6). Lung tumors may be ideal targets for RFA, since the surrounding air in the adjacent normal lung parenchyma can provide an insulating effect, subsequently concentrating the RF energy within the tumor tissue (7). However, according to a previous study, RFA is associated with increased rates of local recurrence for lung tumors with large volumes, since it is difficult to reach sufficiently high temperatures in larger tumors and achieve complete tumor destruction, as the heat source is farther removed from the deeper sections of the tumor (8). Moreover, a rich tumor blood supply is another factor that influences local recurrence, as an abundant blood supply may help to dissipate the thermal energy and weaken the effects of ablation (8). However, as ablative devices are improved, satisfactory ablative margins will likely be achieved. Various scholars suggest 
that even when the tumor is completely destroyed/removed by RFA, residual viable tumor cells within the periphery of the ablated area may repopulate the tumor during a recurrence (9). Therefore, a new view was proposed that local recurrence of the tumor is a product of the biological behaviors of residual tumor cells, since proliferation and angiogenesis potential change with RFA. Overproliferation is mainly observed around areas of tissue necrosis and is associated with a hypoxic tissue microenvironment (10). Therefore, altering the biological characteristics of the hypoxic tissue microenvironment that develops following RFA may influence the local recurrence rate. Therefore, our goal was to observe the tissue microenvironment following RFA and its relationship to recurrence.

The most common patterns of recurrence were classified as local, intrapulmonary or distant. Local recurrence was defined as a recurrence within or at the margin of the ablation site. An intrapulmonary recurrence was defined as the presence of a new tumor within the same lobe as the initially ablated tumor that is separated from the original ablation zone. Distant recurrence was defined as newly identified lung cancer metastases within the other unablated lobe of the ipsilateral lung (11). According to these three patterns, we divided the right lobe that underwent RFA treatment into three distinct regions. We examined the transition zone (TZ) located at the margin of the ablation zone; tumors appearing here were considered a local recurrence. We also examined the reference zone (RZ) of the ablated lobe, which consisted of the unablated part in the lobe that underwent RFA treatment; tumors appearing here were considered an intrapulmonary recurrence. Finally, we examined the RZ on the ipsilateral side of the unablated lobe; tumors appearing here were considered a distant recurrence. We established a nude mouse model with a metastatic human SCLC to study the impact of RFA on the overproliferation of SCLC cell clusters within these three regions.

Hypoxia inducible factor (HIF)- $1 \alpha$ is a transcription factor whose expression can be induced by hypoxia and which regulates multiple biological processes including angiogenesis, cell proliferation and migration (12). Our pervious results indicated that HIF-1 $\alpha$ can regulate the expression of multiple cytokines and promote the proliferation (13) and angiogenesis potential (14) of SCLCs. Therefore, we aimed to ascertain whether intervention strategies aimed at inhibiting HIF-1 $\alpha$ expression could limit or prevent the overproliferation of residual SCLC cells or reduce the angiogenesis potential of the tissues in the TZ to ultimately decrease the tumor recurrence rate following RFA.

\section{Materials and methods}

Animals and surgical procedures. Male congenital athymic BALB/c nude mice were obtained from the Experimental Animal Center of the Shanghai Jiao Tong University School of Medicine. Mice were maintained under pathogen-free conditions in accordance with established institutional guidance and approved protocols. All experiments were carried out using 6- to 8-week-old mice weighing 16-22 g. Animals were housed under standard laboratory conditions. All surgical procedures were performed under isoflurane inhalation anesthesia. Buprenorfine was injected intramuscularly prior to surgery for perioperative analgesia. All animals received humane care during the experiment under a protocol that was in accordance with institutional guidelines for animal research and was approved by the Ethics and Research Committee of Anhui Medical University.

Cell culture and induction of a nude mouse model with metastatic human SCLCs. The NCI-H446 cell line expressing firefly luciferase (Luc) was obtained from the Shanghai Institutes for Biological Sciences Cell Bank and cultured in RPMI-1640 medium (Sigma-Aldrich Co., St. Louis, MO, USA) supplemented with $10 \%$ fetal bovine serum (FBS; HyClone, Thermo Fisher Scientific, Grand Island, NY, USA) and $100 \mathrm{~g} / \mathrm{ml} \mathrm{kanamycin} \mathrm{at} 37^{\circ} \mathrm{C}$ in humidified atmosphere containing $5 \% \mathrm{CO}_{2}$ and $20 \% \mathrm{O}_{2}$.

All animals were acclimated for at least 7 days prior to the intravenous (i.v.) injection of NCI-H446-Luc. On day 1, NCI-H446-Luc cells were collected and resuspended in phosphate-buffered saline (PBS; Thermo Fisher Scientific) at a concentration of $5 \times 10^{7}$ cells $/ \mathrm{ml}$. Tail vein injections of $100 \mu \mathrm{l}$ of cell solution were administered to each mouse. Tumor metastasis was monitored by in vivo imaging at 1 or 3 weeks following the injection. Chloral hydrate $(100 \mu \mathrm{l})$ was administered by intraperitoneal (i.p.) injection, and the procedure commenced after $5 \mathrm{~min}$. After anesthesia, mice were imaged one at a time for 3 min each using an IVIS Lumina II in vivo imaging system (Caliper Life Sciences, a PerkinElmer Co., Hopkinton, MA, USA). Images were collected for further analysis.

RFA treatment and drug intervention. A multipole RF ablation instrument and bipolar ablation needle were purchased from Beijing Blade Opto-Electronic Technology Development Co., Ltd. In nude mice, a bipolar electrode (outer diameter $1.0 \mathrm{~mm}$, active length $10 \mathrm{~mm}$ ) was used for RFA at $2 \mathrm{~W}$ for $45 \mathrm{sec}$ with complete puncture of the right lung upper lobe, which corresponded to a total energy output of $90 \mathrm{~J}$. RF was applied for $5 \mathrm{~min}$ with the generator output titrated to maintain a designated tip temperature $\left(70^{\circ} \mathrm{C} \pm 2,90 \mathrm{~mA} \pm 20\right)$.

YC-1, 3-(5'-hydroxy-methyl-2'-furyl)-1-benzylindazole (Sigma-Aldrich Co.), possesses antiplatelet activity and decreases hypoxia-induced HIF-1 $\alpha$ accumulation and stability (15). Therefore, YC-1 was dissolved in saline and administered via i.p. injections at a preoperative dose of $100 \mathrm{mg} / \mathrm{kg}$ body weight, followed by postoperative doses of $30 \mathrm{mg} / \mathrm{kg}$ body weight.

PTK787/ZK-222584 (PTK/ZK; MedChem Express, Monmouth Junction, NJ, USA) is a non-selective vascular endothelial growth factor receptor tyrosine kinase inhibitor (16). PTK/ZK was dissolved in polyethyleneglycol 400 and administered twice daily by i.p. injections at a dose of $50 \mathrm{mg} / \mathrm{kg}$ from 1 day prior to RFA.

Experimental design and tumor assay. The effect of RFA on the perinecrotic overproliferation of SCLC micrometastases in nude mouse lungs was assessed. This nude mouse model of human SCLC micrometastases was previously established (17). Altogether 150 mice (evenly divided into female and male genders) with established SCLC micrometastases were involved in the experiment and the experimental analysis, which was carried out in three stages at day 1,7 and 


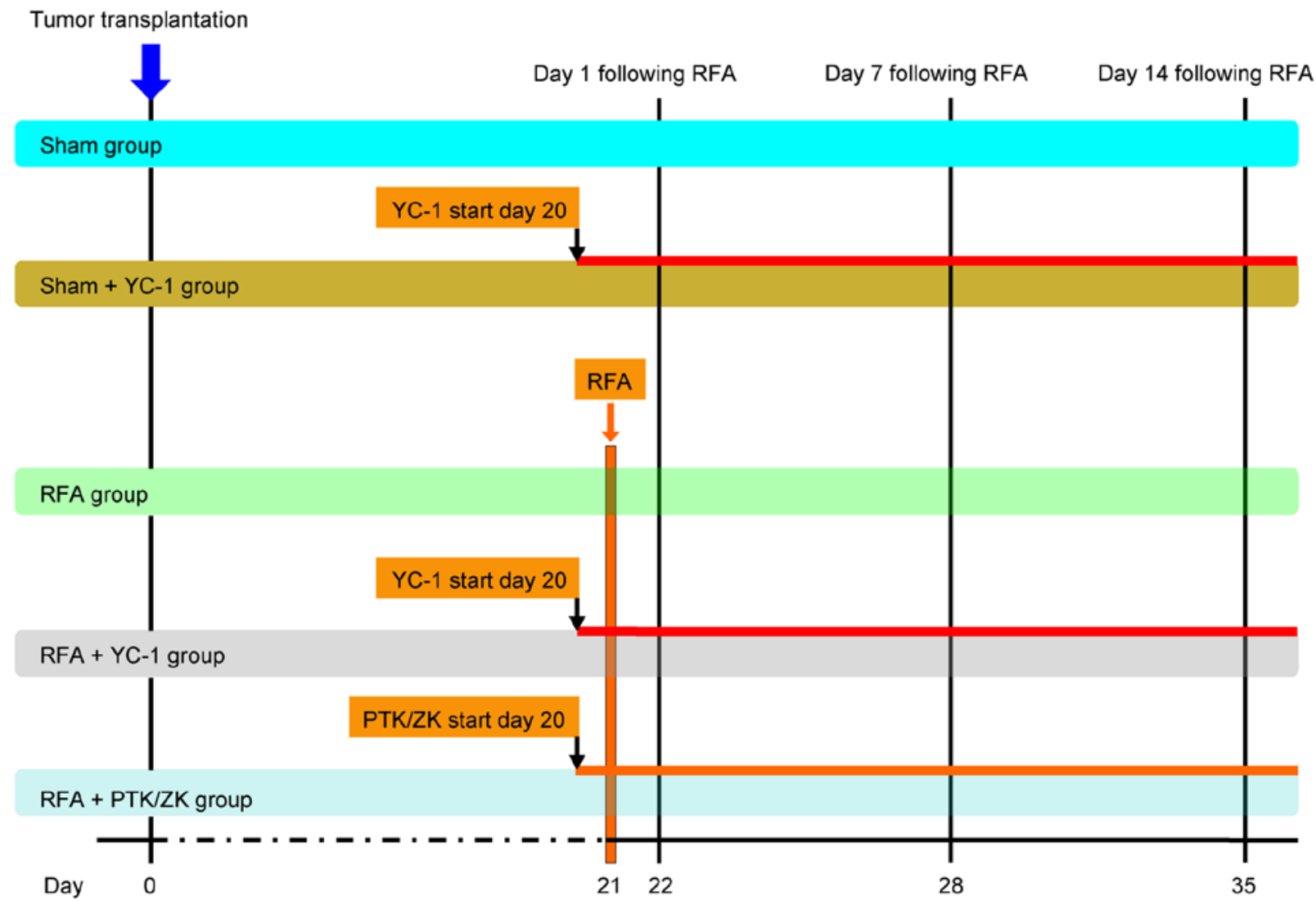

Figure 1. Treatment groups and schedule. A total of 150 mice (evenly divided into female and male genders) were involved in the experiment, and the experimental analysis was carried out in three stages at day 1,7 and 14 following the RFA treatment. AT each stage, 50 mice were randomized into five groups: the sham group; sham + YC-1 group, RFA group, RFA + YC-1 group, RFA + PTK/ZK group, and each group had 10 mice. The treatment plan was as follows. Tail vein injections of NCI-H446 cells in each animal occurred on day 0. RFA treatment began 3 weeks following the injection of tumor cells. Treatment with YC-1 or PTK/ZK was initiated one day before RFA treatment. Mice were individually sacrificed at day 1, 7 and 10 following RFA treatment (n=10/group/time point).

14 following the RFA treatment. In each stage, 50 mice were randomized into five groups: the sham group; sham + YC-1 group; RFA group; RFA + YC-1 group; RFA + PTK/ZK group, and each group had 10 mice. The treatment plan is shown in Fig. 1. Mice were individually sacrificed at day 1, 7 and 10 following RFA treatment ( $n=10 /$ group/time point). Then, the lungs were harvested and fixed in $4 \%$ buffered formaldehyde and embedded in paraffin for morphological assessment of tumor proliferation.

For tumor assays, we applied the methods of Nijkamp et al (16). Tumor load in the lung was scored as the pneumonic replacement area (PRA), which is the percentage of lung tissue that had been replaced by tumor tissue. The PRA in the TZ and RZ was measured. We defined the TZ based on preliminary histologic data, showing histologic characteristics in the TZ that were most abundant in the first $2 \mathrm{~mm}$ stretching from the edge of the central necrosis zone (CZ). RZ was defined as the remaining part of the ipsilateral lung tissue and included the RZ of the right lung upper lobe (RUL) and the RZ of the right lung lower lobe (RLL). All analyses were performed by at least two independent observers that were blinded to the treatment, and used an automated microscope with an interactive video overlay system (Leica Q-Prodit; Leica Microsystems, Rijswijk, The Netherlands). The scar tissue induced by RFA was excluded from analysis. For analysis of treatment with $\mathrm{YC}-1$ and $\mathrm{PTK} / \mathrm{ZK}$, we compared the PRA ratios, the ratio between the PRA in the TZ and the PRA in the RZ. PRA ratios were used to reflect the level of tumor proliferation.

Immunohistochemistry detection for identification of human SCLC metastasis and HIF-1 $\alpha$, and CD34 expression in tumor tissues. All tumor tissues were sectioned into 4- $\mu \mathrm{m}$ slices, deparaffinized, and endogenous peroxidases were inhibited with $0.3 \%$ hydrogen peroxide in methanol for $30 \mathrm{~min}$. Antigen retrieval was achieved by treating sections with $0.05 \%$ protease XIV for $5 \mathrm{~min}$ at $37^{\circ} \mathrm{C}$. Sections were then incubated with a mouse anti-human NSE, HIF-1 $\alpha$ and CD34 primary antibody (NSE, 1:50; HIF-1 $\alpha, 1: 1,000$; CD34, 1:200 dilution; Wuhan Boster Biological Engineering Technology Co. Ltd.) overnight at $4^{\circ} \mathrm{C}$. The slides were then incubated with a biotin-conjugated rabbit anti-mouse secondary antibody (1:1,000; Wuhan Boster Biological Engineering Technology Co. Ltd.) at room temperature for $45 \mathrm{~min}$. The sections were subsequently incubated with a streptavidin-biotin-peroxidase complex (Vectastain ABC kit; Vector Laboratories, Burlingame, CA, USA) at room temperature for $45 \mathrm{~min}$. The reaction was visualized by applying chromogen diaminobenzidine (DAB) for $10 \mathrm{sec}$. Finally, the slides were counterstained with hematoxylin and mounted. The slides were examined with a Nikon Eclipse Ti microscope under a x40 objective (Nikon Instruments, Melville, NY, USA). Images of all 

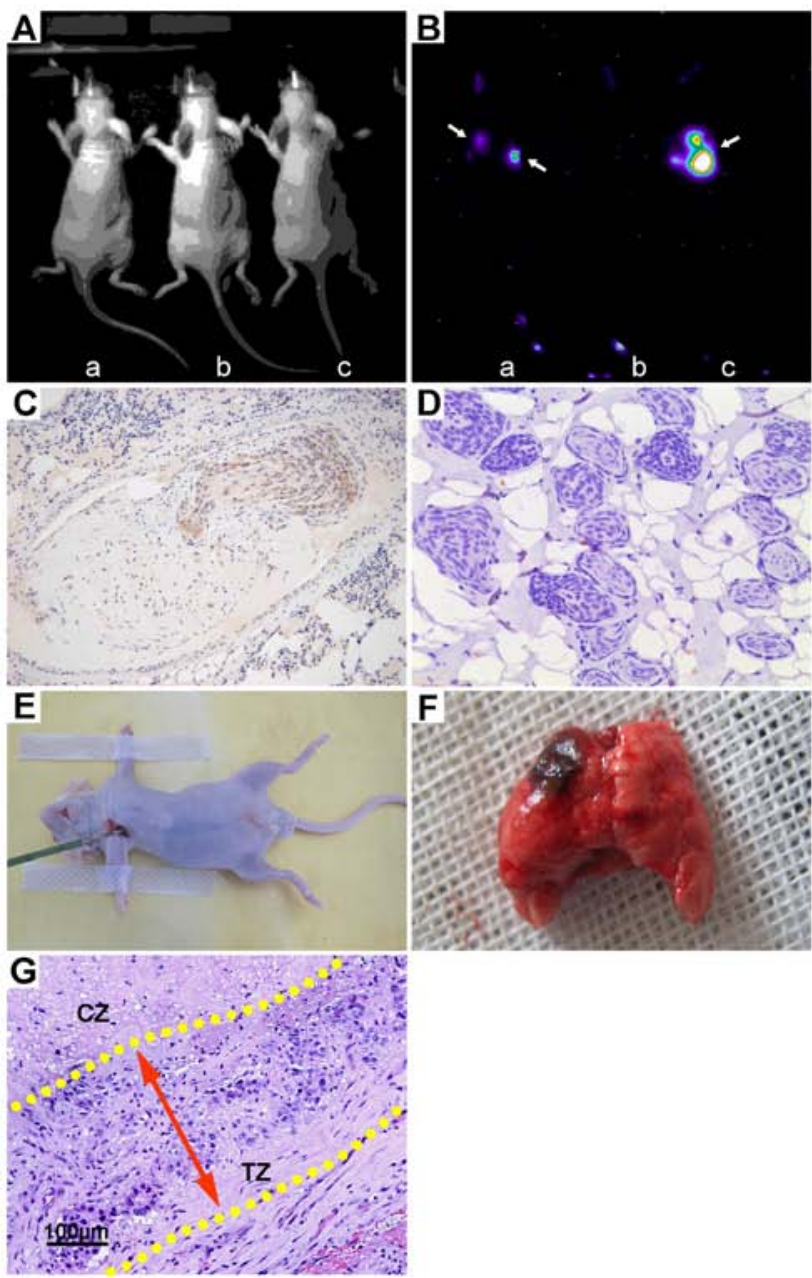

H

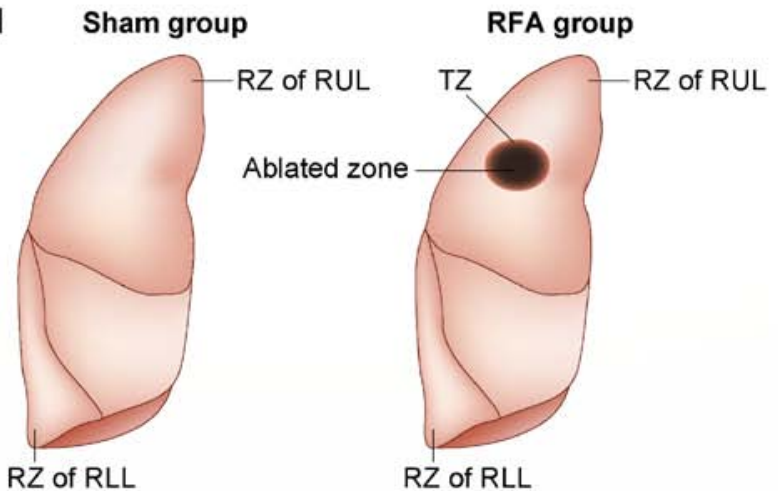

Figure 2. Establishment of an experimental model of human SCLC metastasis and RFA treatment. (A and B) Following injection of NCI-H446-Luc cells, metastatic human SCLCs occurred in the bilateral lobe as shown by fluorescent display (the arrows show: a group, 1 week following injection; $\mathrm{b}$ group, no treatment; c group, 3 weeks following injection). (C and D) One week following the injection, histological slices of mouse lung showed that the tumor tissue cluster of human SCLCs occurred close to the pulmonary bronchium or vessel and NSE expression as positive area of DAB staining occurred within the metastasis. Then, 3 weeks following injection of human SCLC cells, metastasis widely grew within the lung tissue. (E and F) After anesthesia, the mice underwent right upper lobe puncture treatment. The depth of needle percutaneous puncture was $0.5 \mathrm{~cm}$, and the necrotic ablation area formed was $\sim 0.3-0.5 \mathrm{~cm}$ in diameter. (G) Histological slices of the tissue around the necrotic central area $(\mathrm{CZ})$ showed that necrotic area transferred to the normal tissue and the transition zone (TZ) was formed. In this area the proliferation of the human SCLC metastasis was observed. (H) TZ was defined as the area stretching $2 \mathrm{~mm}$ outside the necrotic central zone. RZ was defined as the remaining part of the ipsilateral lung tissue and included the $\mathrm{RZ}$ of the right lung upper lobe (RUL) or the RZ of the right lung lower lobe (RLL).
A Day 1 tumor growth of RFA groupvs. sham group

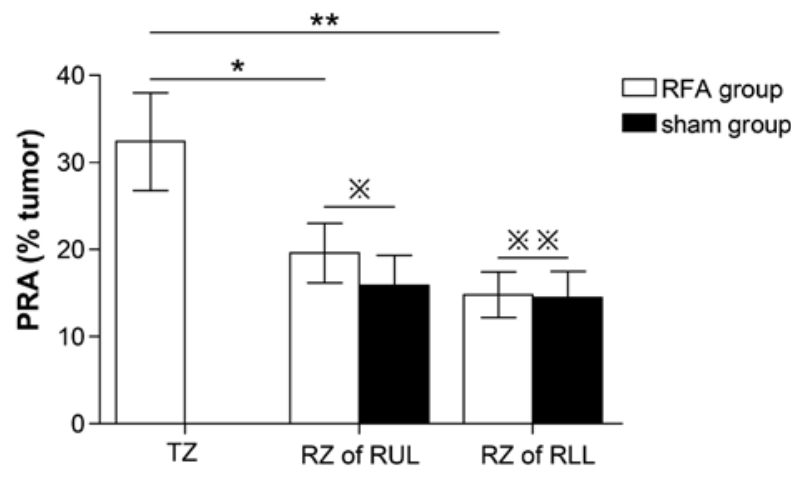

B Day 7 tumor growth of RFA group vs. sham group

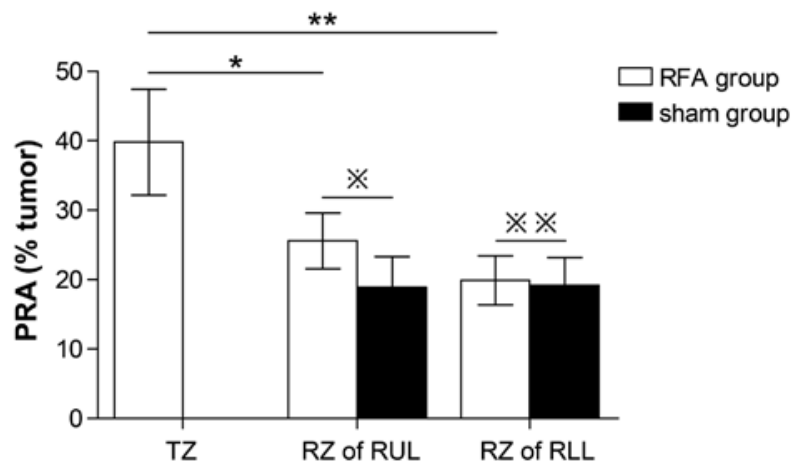

C Day 14 tumor growth of RFA group vs. sham group

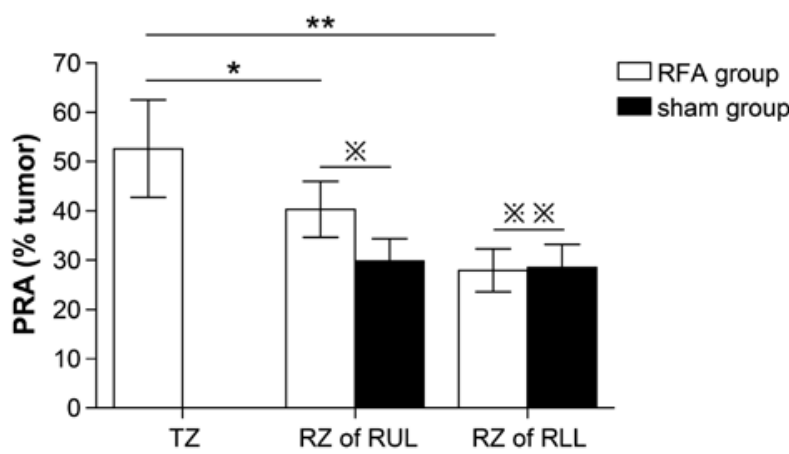

Figure 3. Accelerated perilesional outgrowth of established micrometastases following RFA in the TZ and RZ. (A-C) Tumor growth at day 1, 7 and 14 following RFA treatment, expressed as the PRA in the TZ, defined as the area extending $2 \mathrm{~mm}$ outside the necrotic lesion in the RUL and RZ defined as the remaining part of the RUL and free area of the RLL. (A) Day 1: * $* \mathrm{p}=0.96$, $\mathrm{RZ}$ of RFA group vs. RZ of sham group in RLL; * $\mathrm{p}=0.036, \mathrm{RZ}$ of RFA group vs. $R Z$ of sham group in RUL; ; $\mathrm{p}=0.000$, TZ vs. RZ in RLL; and " $\mathrm{p}=0.008$, TZ vs. RZ in RUL. (B) Day 7: * * p=0.87, RZ of RFA group vs. RZ of sham group in RLL; * $=0.021, R Z$ of RFA group vs. RZ of sham group in RUL; ${ }^{* *} \mathrm{p}=0.001, \mathrm{TZ}$ vs. RZ in RLL and ${ }^{*} \mathrm{p}=0.011, \mathrm{TZ}$ vs. RZ in RUL. (C) Day 14: * $\mathrm{p}=0.89, \mathrm{RZ}$ of RFA group vs. $\mathrm{RZ}$ of sham group in $\mathrm{RLL}$ and $* \mathrm{p}=0.019, \mathrm{RZ}$ of RFA group vs. RZ of sham group in RUL; ${ }^{* *} \mathrm{p}=0.006, \mathrm{TZ}$ vs. RZ in RLL and ${ }^{*} \mathrm{p}=0.026, \mathrm{TZ}$ vs. RZ in RUL.

fields directly surrounding the lesion in one representative slide/tumor (6-13 fields/slide) were selected. The percentage of positive areas in each field was calculated with ImageJ software (National Institutes of Health, Bethesda, MD, USA).

Statistical analysis. Statistical differences between groups were analyzed by a Student's t-test and ANOVA for parametric data. Data are expressed as mean \pm SEM. $\mathrm{p}<0.05$ or $\mathrm{p}<0.01$ was set as the level of statistical significance. 
Table I. HPR value (\%) in TZ and RZ at days 1,7 and 14 following RFA.

A, HPR value (\%) in TZ and RZ at day 1 following RFA

\begin{tabular}{lllll}
\hline Group & TZ & RZ in RUL & RZ in RLL & \\
\hline RFA & $32.4 \pm 5.62$ & $19.6 \pm 3.46$ & $14.8 \pm 2.98$ & $\begin{array}{l}\mathrm{p}=0.000 \mathrm{TZ} \text { vs. RZ in RLL of RFA group } \\
\mathrm{p}=0.008 \mathrm{TZ} \text { vs. RZ in RUL of RFA group } \\
\mathrm{p}=0.036 \mathrm{HPR} \text { of RZ in RUL RFA group vs. sham group } \\
\mathrm{p}=0.96 \text { HPR of RZ in RLL RFA group vs. sham group }\end{array}$ \\
\hline
\end{tabular}

$\mathrm{B}, \mathrm{HPR}$ value (\%) in TZ and RZ at day 7 following RFA

\begin{tabular}{|c|c|c|c|c|}
\hline Group & $\mathrm{TZ}$ & $\mathrm{RZ}$ in RUL & RZ in RLL & P-value \\
\hline RFA & $39.8 \pm 7.62$ & $25.6 \pm 4.42$ & $19.9 \pm 3.98$ & $\begin{array}{l}\mathrm{p}=0.001 \mathrm{TZ} \text { vs. RZ in RLL of RFA group } \\
\mathrm{p}=0.011 \mathrm{TZ} \text { vs. RZ in RUL of RFA group }\end{array}$ \\
\hline Sham & & $18.9 \pm 3.99$ & $19.2 \pm 3.52$ & $\begin{array}{l}\mathrm{p}=0.021 \mathrm{HPR} \text { of RZ in RUL RFA group vs. sham group } \\
\mathrm{p}=0.87 \mathrm{HPR} \text { of RZ in RLL RFA group vs. sham group }\end{array}$ \\
\hline
\end{tabular}

$\mathrm{C}, \mathrm{HPR}$ value (\%) in $\mathrm{TZ}$ and $\mathrm{RZ}$ at day 14 following RFA

\begin{tabular}{|c|c|c|c|c|}
\hline Group & $\mathrm{TZ}$ & $\mathrm{RZ}$ in RUL & $\mathrm{RZ}$ in RLL & P-value \\
\hline RFA & $52.6 \pm 9.89$ & $40.3 \pm 5.69$ & $27.9 \pm 4.39$ & $\begin{array}{l}\mathrm{p}=0.009 \mathrm{TZ} \text { vs. RZ in RLL of RFA group } \\
\mathrm{p}=0.026 \mathrm{TZ} \text { vs. RZ in RUL of RFA group }\end{array}$ \\
\hline Sham & & $29.8 \pm 4.53$ & $28.5 \pm 4.74$ & $\begin{array}{l}\mathrm{p}=0.019 \mathrm{HPR} \text { of RZ in RUL RFA group vs. sham group } \\
\mathrm{p}=0.89 \mathrm{HPR} \text { of RZ in RLL RFA group vs. sham group }\end{array}$ \\
\hline
\end{tabular}

TZ, transition zone; RZ, reference zones; RFA, radiofrequency ablation; RUL, right upper lobe; RLL, right lower lobe.

\section{Results}

RFA treatment effects and the TZ in lung tissue are morphologically distinct. We implanted a luciferase-labeled subline of the human variant SCLC cell line NCI-H446 orthotopically into the right lung of nude mice to establish an SCLC metastasis model. Three weeks following tail vein injection of SCLC cells, signs of systemic failure became increasingly more apparent, which included emaciation, lethargy and hunching of the back. Imaging was performed to assess fluorescence in the lung to locate and quantify the luciferase-labeled cancer cells, which could be used as an overall metric to quantify metastatic behavior (Fig. 2A and B). Histological observations revealed that the SCLC tumor tissue tended to cluster close to the pulmonary bronchium and vessel. In addition, human NSE expression was evaluated as the positive area of DAB staining observed within the tumor tissue. Since NSE is a specific marker of human SCLC cells, we used NSE expression to verify that the transplantation tumor was indeed derived from human SCLC cells (Fig. 2C). By 3 weeks following injection, human SCLC metastasis became prominent and pervasive throughout the lung tissue (Fig. 2D). All the mice were then anesthetized and subjected to RFA treatment in the RUL. The depth of needle percutaneous puncture was $0.5 \mathrm{~cm}$ and this formed the ablation area (Fig. 2E and F). Histological sections showed that the $\mathrm{TZ}$ stretched $2 \mathrm{~mm}$ outside the necrotic central area and any local recurrences often occurred in this area (Fig. 2G). With thermal ablation, the TZ and RZ in the RUL exhibited a different microenvironment as compared to $\mathrm{RZ}$ in the RLL, representing a different region of recurrence (Fig. 2H).

RFA accelerates the outgrowth of human SCLC micrometastases in the $T Z$ and $R Z$ of the lobe that underwent RFA. The first parameter analyzed was PRA, or the percentage of lung tissue that had been replaced by tumor tissue. Measuring the tumor size reflects proliferation. The PRA value of the RZ in the RLL showed that at day 1, 7 and 14 following RFA treatment, no significant changes could be observed when comparing the RFA group with the sham group (day $1 \mathrm{RFA}, 14.8 \pm 2.98 \%$ vs. sham, $14.5 \pm 2.62 \%, \mathrm{p}=0.96$; day 7 RFA, $19.9 \pm 3.98 \%$ vs. sham, $19.2 \pm 3.52 \%, \mathrm{p}=0.87$; day $14 \mathrm{RFA}, 27.9 \pm 4.39 \%$ vs. sham, $28.5 \pm 4.47 \%, \mathrm{p}=0.89)$. These data indicated that RFA did not affect the outgrowth of metastases in the lobe not undergoing RFA treatment (Fig. 3A-C; Table IA-C). However, the RZ in the RUL showed a significantly higher PRA value in the RFA group when compared with the sham group (day 1 RFA, 19.6 $\pm 3.46 \%$ vs. sham, $15.9 \pm 3.43 \%, \mathrm{p}=0.036$; day $7 \mathrm{RFA}, 25.6 \pm 4.42 \%$ vs. sham, $18.9 \pm 3.99 \% \mathrm{p}=0.021$; day $14 \mathrm{RFA}, 40.3 \pm 5.69 \%$ vs. sham, $29.8 \pm 4.53 \%, \mathrm{p}=0.019$ ) (Fig. 3A-C; Table IA-C). 

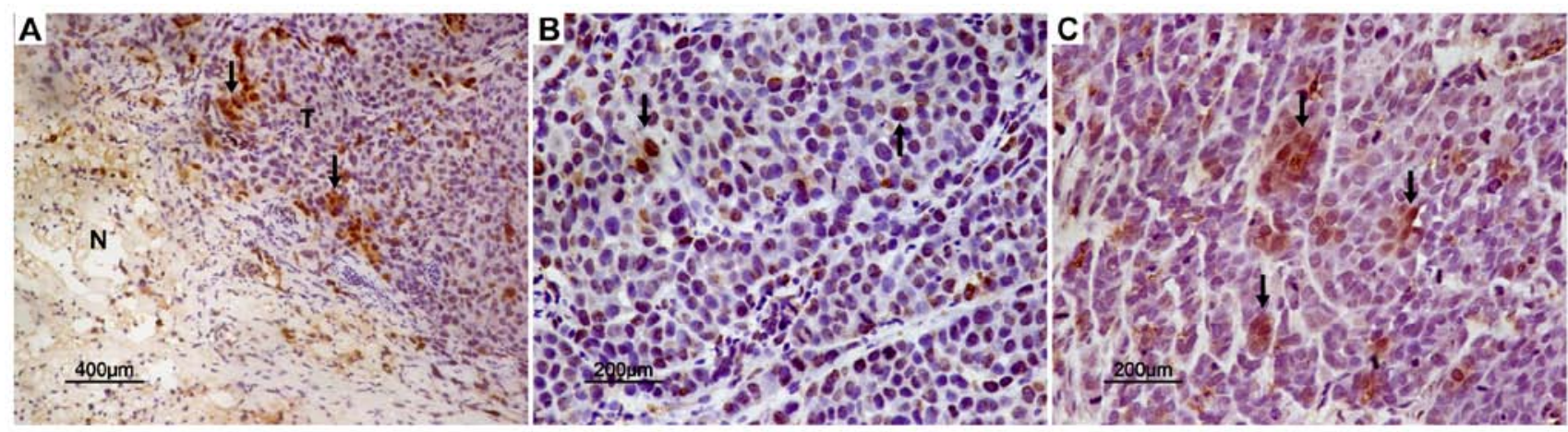

D HIF-1 $\alpha$ expression in TZ and RZ

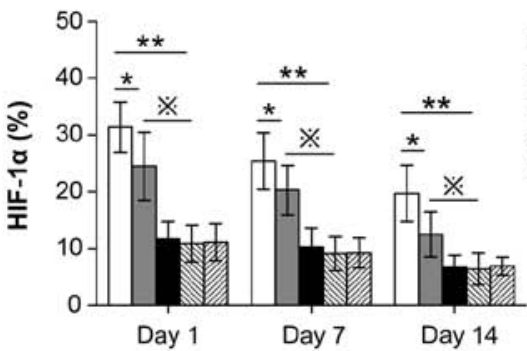

F PRA of RZ in right upper lobe

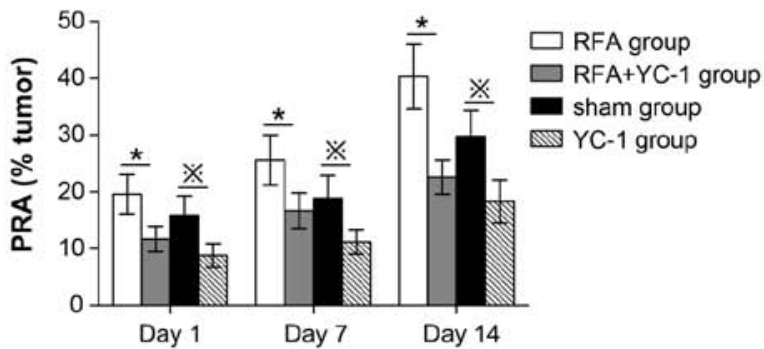

E PRA of TZ in right lower lobe

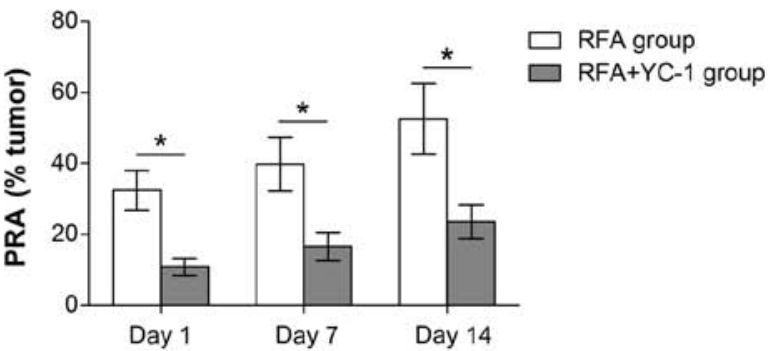

G PRA of RZ in right lower lobe

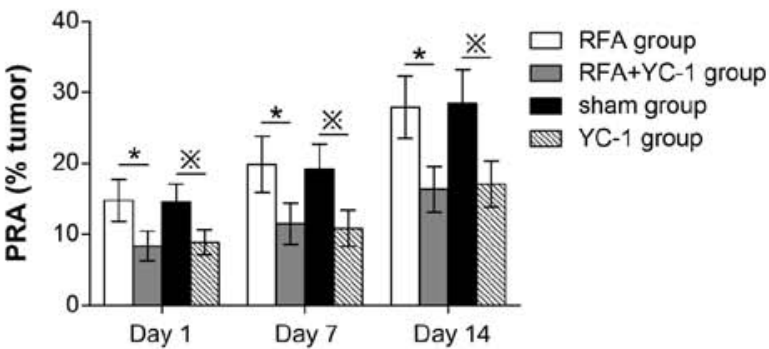

Figure 4. Regardless of the TZ or RZ, tumor growth was induced by HIF-1 $\alpha$ at day 1, 7 and 14 following RFA treatment. (A-C) Immunostaining showed the HIF-1 $\alpha$ expression as brown tumor cells (arrows) in tumor tissue (T) of TZ (A) adjacent to the necrosis ablated zone (N), RZ in RUL (B) and RZ in RLL (C). (D) Results of the semi-quantitative analysis and comparison of the HIF-1 $\alpha$ expression level in the TZ and RZ of the RUL and RLL at day 1, 7 and 14: day 1, "p=0.028 TZ vs. RZ in RUL and " $\mathrm{p}=0.001 \mathrm{TZ}$ vs. RZ in RLL; day 7, "p=0.037 TZ vs. RZ in RUL and "* $\mathrm{p}=0.007 \mathrm{TZ}$ vs. RZ in RLL; day 14 , ${ }^{*} \mathrm{p}=0.014 \mathrm{TZ}$ vs. RZ in RUL and ${ }^{* *} \mathrm{p}=0.000 \mathrm{TZ}$ vs. RZ in RLL. In addition these, the HIF-1 $\alpha$ expression level was higher in the RZ of the RUL than the RZ of the RLL. Day 1 , *p=0.005 RZ in RUL vs. RZ in RLL; day 7, *p=0.011 RZ in RUL vs. RZ in RLL; day 14, *p=0.021 RZ in RUL vs. RZ in RLL. (E) Treatment with YC-1 decreased the PRA value significantly: "p $\leq 0.001$, RFA group vs. RFA + YC-1 group at day 1, 7 and 14. (F and G) PRA value of RZ in RUL and RLL decreased in the RFA + YC-1 group at days 1, 7 and 14: "p<0.01, RFA group vs. RFA + YC-1 group. Meanwhile in the sham group, the PRA value also decreased after treatment with YC-1: * $\mathrm{p}<0.05$ sham vs. YC-1 group.

RFA induced a significant increase in the amount of tumor tissue in the TZ surrounding the ablated region as compared with the RZ in the same lobe (day $1 \mathrm{TZ}, 32.4 \pm 5.62 \%$ vs. RZ, $19.6 \pm 3.46 \%, \mathrm{p}=0.008$; day $7 \mathrm{TZ}, 39.8 \pm 7.62 \%$ vs. RZ, $25.6 \pm 4.42 \%, \mathrm{p}=0.011$; day $14 \mathrm{TZ}, 52.6 \pm 9.89 \%$ vs. RZ, $40.3 \pm 5.69 \%, \mathrm{p}=0.026$ ). There was an $\sim 2$-fold increase in the $\mathrm{TZ}$ compared with the RZ in the RLL (day $1 \mathrm{TZ}, 32.4 \pm 5.62 \%$ vs. RZ, $14.8 \pm 2.98 \%, \mathrm{p}=0.000$; day $7 \mathrm{TZ}, 39.8 \pm 7.62 \%$ vs. $\mathrm{RZ}, 19.9 \pm 3.98 \%, \mathrm{p}=0.001$; day $14 \mathrm{TZ}, 52.6 \pm 9.89 \%$ vs. RZ, $27.9 \pm 4.39 \%, \mathrm{p}=0.006$ ) (Fig. 3A-C; Table IA-C).

These results indicated that RFA treatment induced the proliferation of tumors in the ablated lobe, but did not affect the tumor on the ipsilateral side of the other lobe. In the ablated lobe, the tumor in the $\mathrm{TZ}$ surrounding the ablated region had a higher proliferative capacity than the tumor in the distant areas. The tumor microenvironment may have been altered by RFA treatment, which could help to account for these differences. Therefore, we explored the expression of tumor-relevant regulatory factors within the tumor microenvironment.

Accelerated tumor proliferation in the TZ and $R Z$ is associated with HIF-1 $\alpha$ expression. Based on the immunohistochemical results (Fig. 4A-C) and semi-quantitative analysis, the highest HIF-1 $\alpha$ expression level occurred in the TZ at day 1 following RFA treatment (TZ, $31.4 \pm 4.43 \%$ vs. RZ in RUL, $24.5 \pm 5.79 \%$, $\mathrm{p}=0.028$; TZ, $31.4 \pm 4.43 \%$ vs. RZ in RLL, $10.9 \pm 3.21 \%$, $\mathrm{p}=0.001$ ) (Fig. 4D; Table IIA). At day 1, 7 and 14 following RFA treatment, HIF-1 $\alpha$ expression in the RZ of the ablated lobe was significantly higher in the RFA than the sham group (RFA group vs. sham group; day $1,24.5 \pm 5.97 \%$ vs. $11.7 \pm 3.03 \%$, $\mathrm{p}=0.019$; day $7,20.3 \pm 4.35 \%$ vs. $10.3 \pm 3.32 \%, \mathrm{p}=0.011$; day 14 , $12.5 \pm 3.96 \%$ vs. $6.7 \pm 2.13 \%, \mathrm{p}=0.017$ ), although the expression level in the RZ of RLL showed no significant difference (day 1, p=0.89; day 7, p=0.92; day 14, p=0.96 (Fig. 4D; Table IIA-C). Meanwhile, in the RFA group, thermal stimulus 
Table II. HIF-1 $\alpha$ expression (\%) in TZ and RZ at days 1, 7 and 14 following RFA.

A, HIF-1 $\alpha$ expression (\%) in TZ and RZ at at day 1 following RFA

\begin{tabular}{|c|c|c|c|c|}
\hline Group & $\mathrm{TZ}$ & RZ in RUL & RZ in RLL & P-value \\
\hline RFA & $31.4 \pm 4.43$ & $24.5 \pm 5.97$ & $10.9 \pm 3.21$ & $\begin{array}{l}\mathrm{p}=0.001 \text { RFA group: } \mathrm{TZ} \text { vs. RZ in RLL } \\
\mathrm{p}=0.028 \text { RFA group: } \mathrm{TZ} \text { vs. RZ in RUL } \\
\mathrm{p}=0.019 \text { RZ in RUL: RFA group vs. sham group }\end{array}$ \\
\hline Sham & & $11.7 \pm 3.03$ & $11.1 \pm 3.24$ & $\begin{array}{l}\mathrm{p}=0.89 \text { RZ in RLL: RFA group vs. sham group } \\
\mathrm{p}=0.005 \text { RFA group: RZ in RUL vs. RZ in RLL }\end{array}$ \\
\hline
\end{tabular}

B, HIF-1 $\alpha$ expression (\%) in TZ and RZ at day 7 following RFA

\begin{tabular}{|c|c|c|c|c|}
\hline Group & $\mathrm{TZ}$ & RZ in RUL & RZ in RLL & P-value \\
\hline RFA & $25.4 \pm 5.01$ & $20.3 \pm 4.35$ & $9.1 \pm 2.98$ & $\begin{array}{l}\mathrm{p}=0.007 \text { RFA group: } \mathrm{TZ} \text { vs. RZ in RLL } \\
\mathrm{p}=0.037 \text { RFA group: } \mathrm{TZ} \text { vs. RZ in RUL } \\
\mathrm{p}=0.011 \mathrm{RZ} \text { in RUL: RFA group vs. sham group }\end{array}$ \\
\hline Sham & & $10.3 \pm 3.32$ & $9.2 \pm 2.64$ & $\begin{array}{l}\mathrm{p}=0.92 \mathrm{RZ} \text { in RLL: RFA group vs. sham group } \\
\mathrm{p}=0.011 \text { RFA group: RZ in RUL vs. RZ in RLL }\end{array}$ \\
\hline
\end{tabular}

C, HIF-1 $\alpha$ expression (\%) in TZ and RZ at day 14 following RFA

\begin{tabular}{|c|c|c|c|c|}
\hline Group & $\mathrm{TZ}$ & RZ in RUL & $\mathrm{RZ}$ in RLL & P-value \\
\hline RFA & $19.7 \pm 4.97$ & $12.5 \pm 3.96$ & $6.4 \pm 2.78$ & $\begin{array}{l}\mathrm{p}=0.000 \text { RFA group: } \mathrm{TZ} \text { vs. RZ in RLL } \\
\mathrm{p}=0.014 \text { RFA group: } \mathrm{TZ} \text { vs. RZ in RUL } \\
\mathrm{p}=0.017 \text { RZ in RUL: RFA group vs. sham group }\end{array}$ \\
\hline Sham & & $6.7 \pm 2.13$ & $6.9 \pm 1.58$ & $\begin{array}{l}\mathrm{p}=0.96 \mathrm{RZ} \text { in RLL: RFA group vs. sham group } \\
\mathrm{p}=0.021 \text { RFA group: RZ in RUL vs. RZ in RLL }\end{array}$ \\
\hline
\end{tabular}

HIF-1 $\alpha$, hypoxia inducible factor-1 $\alpha$; TZ, transition zone; RZ, reference zones; RFA, radiofrequency ablation; RUL, right upper lobe; RLL, right lower lobe.

more significantly increased HIF-1 $\alpha$ expression in the RZ of the ablated lobe in RUL than RZ of the non-ablated lobe in RLL at day 1, 7 and 14 (RZ of RUL vs. RZ of RLL: day 1, $24.5 \pm 5.79 \%$ vs. $10.9 \pm 3.21 \%, \mathrm{p}=0.005$; day $7,20.3 \pm 4.35 \%$ vs. $9.1 \pm 2.98 \%, \mathrm{p}=0.011$; day $14,12.5 \pm 3.96 \%$ vs. $6.4 \pm 2.78 \%$, $\mathrm{p}=0.021$ ) (Fig. 4D; Table IIA-C). Following treatment with YC-1, an inhibitor of HIF-1 $\alpha$, the PRA value in the TZ significantly decreased at days 1,7 and 14 following RFA (RFA group vs. RFA + YC-1 group: day $1,32.4 \pm 5.62 \%$ vs. $10.8 \pm 2.34 \%$, $\mathrm{p}=0.000$; day $7,39.8 \pm 7.62 \%$ vs. $16.6 \pm 3.98 \%, \mathrm{p}=0.000$; day 14 , $52.6 \pm 9.89 \%$ vs. $23.5 \pm 4.74 \%, \mathrm{p}=0.001$ ) (Fig. 4E; Table IIIA). In addition to the $\mathrm{TZ}$, tumor proliferation capacity was also inhibited by YC-1 in the RZ of the RUL and RLL, regardless of RFA treatment (Fig. 4F and G; Table IIIA and B; data not shown). These data suggest that tumor proliferation was universally induced by HIF-1 $\alpha$ and can be suppressed by inhibiting HIF-1 $\alpha$. Thermal stimulus had the greatest impact on HIF-1 $\alpha$ expression; HIF- $1 \alpha$ reached its highest expression levels in the TZ surrounding the central necrotic zone. In addition, RFA treatment induced HIF-1 $\alpha$ expression in the distant region (RZ) of the ablation zone.
Tissue angiogenesis potential is also regulated by $\mathrm{HIF}-1 \alpha$, but has no effect on tumor proliferation in the TZ. As demonstrated, accelerated tumor growth in the $\mathrm{TZ}$ or $\mathrm{RZ}$ of the ablated lobe following RFA was found to be associated with activation of HIF-1 $\alpha$. Our pervious study indicated that HIF-1 $\alpha$ can induce the expression of multiple angiogenic cytokines, while upregulating the angiogenesis potential of SCLC cells. Therefore, we set out to determine whether tissue angiogenesis acts as the driving force in RFA-stimulated micrometastasis growth. To assess the effects on the growth of micrometastases by angiogenesis, we analyzed the microvessel density (MVD) as CD34-positive stained areas to compare the angiogenesis potential of the TZ and RZ in the RUL and RLL (Fig. 5A-C). At days 1, 7 and 14 following RFA treatment, the TZ exhibited a higher angiogenesis potential in the CD34-positive area compared with the RZ in the RUL (such as: day $1 \mathrm{TZ}, 156.7 \pm 30.99 \%$ vs. $\mathrm{RZ}, 127.8 \pm 24.34 \%, \mathrm{p}=0.011$ ) and RZ in RLL (such as: day 1, TZ, 156.7 $\pm 30.99 \%$ vs. RZ, $119.8 \pm 19.90 \%, p=0.002$ ) (Fig. 5D, Table IVA-C). Treatment with YC-1 reduced CD34 expression in all zones following RFA (day $1 \mathrm{TZ}, 156.7 \pm 30.99 \%$ vs. $82.2 \pm 20.67 \%$ p=0.00; RZ 
Table III. PRA value (\%) in TZ, RZ of RUL and RZ of RLL at days 1, 7 and 14.

A, PRA value $(\%)$ in TZ

\begin{tabular}{|c|c|c|c|c|}
\hline Group & Day 1 & Day 7 & Day 14 & P-value \\
\hline RFA & $32.4 \pm 5.62$ & $39.8 \pm 7.62$ & $52.6 \pm 9.89$ & $\begin{array}{l}\text { Day } 1, p=0.000 \text { RFA group vs. RFA }+Y C-1 \text { group } \\
\text { Day } 7, p=0.000 \text { RFA group vs. RFA }+Y C-1 \text { group }\end{array}$ \\
\hline $\mathrm{RFA}+\mathrm{YC}-1$ & $10.8 \pm 2.34$ & $16.6 \pm 3.98$ & $23.5 \pm 4.74$ & Day $14, p=0.001$ RFA group vs. RFA + YC-1 group \\
\hline
\end{tabular}

$\mathrm{B}, \mathrm{PRA}$ value $(\%)$ in RZ of RUL

\begin{tabular}{lrlll}
\hline Group & Day 1 & Day 7 & Day 14 & P-value \\
\hline RFA & $19.6 \pm 3.46$ & $25.6 \pm 4.42$ & $40.3 \pm 5.69$ & Compared with RFA and RFA + YC-1 group; \\
RFA + YC-1 & $11.7 \pm 2.23$ & $16.7 \pm 3.12$ & $22.6 \pm 3.01$ & day 1, p=0.008, day 7, p=0.006, day 14, p=0.000 \\
Sham & $15.9 \pm 3.43$ & $18.9 \pm 3.99$ & $29.8 \pm 4.53$ & Compared with sham and YC-1 group; \\
YC-1 & $8.8 \pm 2.08$ & $11.2 \pm 2.15$ & $18.3 \pm 3.79$ & day 1, p=0.012, day 7, p=0.024, day 14, p=0.031 \\
\hline
\end{tabular}

C, PRA value (\%) in RZ of RLL

\begin{tabular}{lrlll}
\hline Group & \multicolumn{1}{c}{ Day 1 } & Day 7 & Day 14 & P-value \\
\hline RFA & $14.8 \pm 2.98$ & $19.9 \pm 3.98$ & $27.9 \pm 4.39$ & Compared with RFA group and RFA+ YC-1 group; \\
RFA + YC-1 & $8.4 \pm 2.09$ & $11.5 \pm 2.87$ & $16.4 \pm 3.21$ & day 1, p=0.020, day 7, p=0.026, day 14, p=0.008 \\
Sham & $14.5 \pm 2.62$ & $19.2 \pm 3.52$ & $28.5 \pm 4.74$ & Compared with sham group and YC-1 group; \\
YC-1 & $8.9 \pm 1.78$ & $10.9 \pm 2.55$ & $17.1 \pm 3.24$ & day 1, p=0.037, day 7, p=0.029, day 14, p=0.011 \\
\hline
\end{tabular}

TZ, transition zone; RZ, reference zones; RFA, radiofrequency ablation; RUL, right upper lobe; RLL, right lower lobe.

in RUL: $127.8 \pm 24.34 \%$ vs. $43.1 \pm 8.65 \% \mathrm{p}=0.00$; RZ in RLL: $119.8 \pm 19.90 \%$ vs. $37.8 \pm 7.12 \%$ p=0.000) (Fig. $5 D$; Table IVA-C). However, treatment with the vascular specific inhibitor PTK/ ZK did not alter tumor growth in the TZ (day 1 PRA of TZ: $32.4 \pm 5.62$ vs. $31.6 \pm 5.37, \mathrm{p}=0.87$ ), which was different from the results of the RZ in the RUL and RLL (Fig. 5E; Table VA-C; data not shown). Our data indicated that HIF-1 $\alpha$ regulates tumor growth by inducing tissue angiogenesis in the RZ of the RUL and the RLL. However, in the TZ in RFA-treated mice, tumor growth was not associated with tissue angiogenesis potential, although regulated by HIF- $1 \alpha$.

In conclusion, we found the following. i) Following RFA treatment, the $\mathrm{TZ}$ formed between the central necrotic zone and the unaffected RZ along with the micrometastasis in this zone exhibited stronger proliferative activity and higher HIF-1 $\alpha$ expression levels than the other zones. The growth of micrometastases in the TZ was induced by HIF-1 $\alpha$, but was not associated with the tissue angiogenesis potential. ii) In the RZ of the ablated or unablated lobe, HIF-1 $\alpha$ induced the growth of micrometastases by regulating tissue angiogenesis potential.

\section{Discussion}

Radiofrequency ablation (RFA) is a thermal ablative technique and a relatively new modality of treatment, which may be applicable in high-risk patients with lung cancer (18). Compared with radiotherapy and chemotherapy, RFA is focused exclusively on the tumor area and does not damage the normal surrounding tissue. Compared with surgical intervention, RFA is minimally invasive. For advanced lung cancers, including small cell lung cancer (SCLC), RFA also can enhance palliative treatment (19). In general, RFA appears to be a safe procedure with limited/minimal morbidity and mortality (20). The most common operation complication appears to be the occasional development of a pneumothorax or hemothorax. However, with the progression in hemostasis techniques and surgical repair materials, the incidence of these complications will be significantly reduced (21). Although RFA has been increasingly more widely used for the treatment of lung cancer, postoperative recurrence is still a major shortcoming of this therapy (8). Various scholars argue that recurrences may be managed or mitigated based on a careful distinction of the recurrence site. Based on this concept, when regional hilar mediastinal lymphatic metastasis or distant relapse occurs, patients should be considered as affected by systemic tumor factors; initial ablation was probably complete, but the stage was underestimated and the patients should be managed by systemic therapy. If a tumor recurrence occurs in the local area surrounding the ablation zone, patients should be considered as being affected by the local tumor microenvironmental changes, and ablation was probably incomplete (22).

For the recurrence of malignant tumors following RFA, previous research indicates that increasing tumor size is 
A
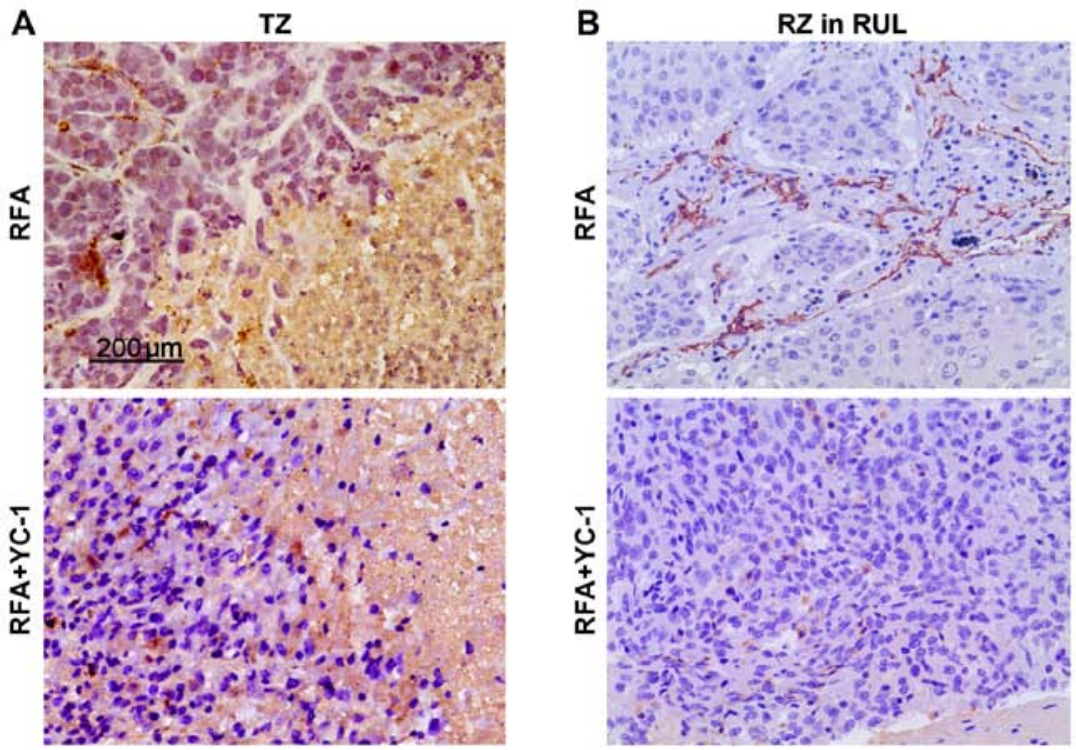

C

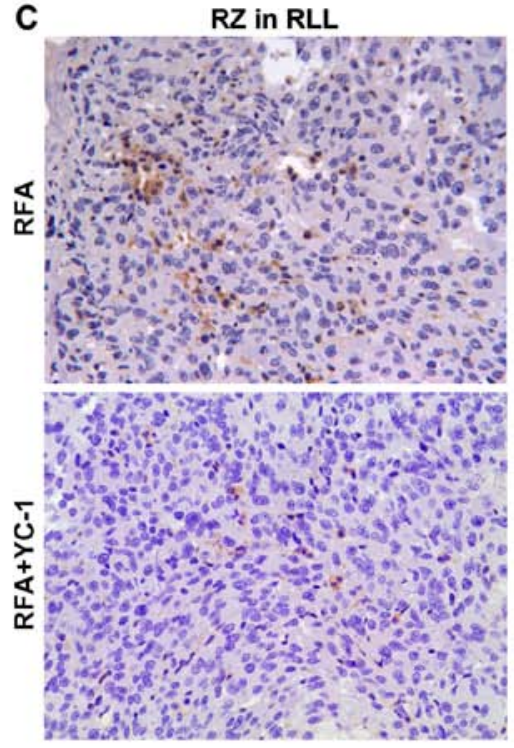

Day 7
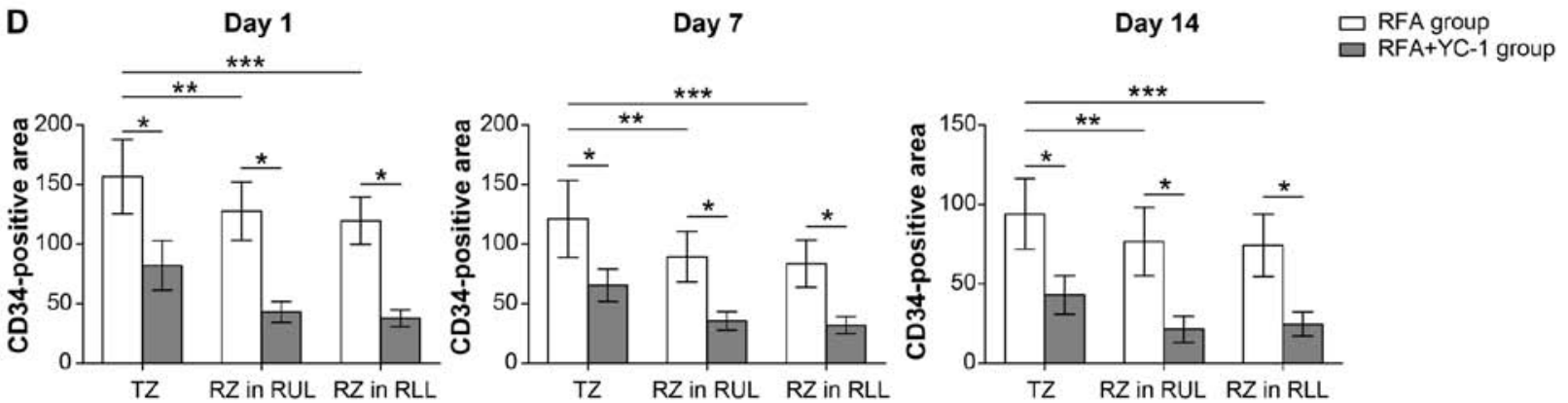

E PRA of TZ in right upper lobe

PRA of RZ in right upper lobe

PRA of RZ in right lower lobe
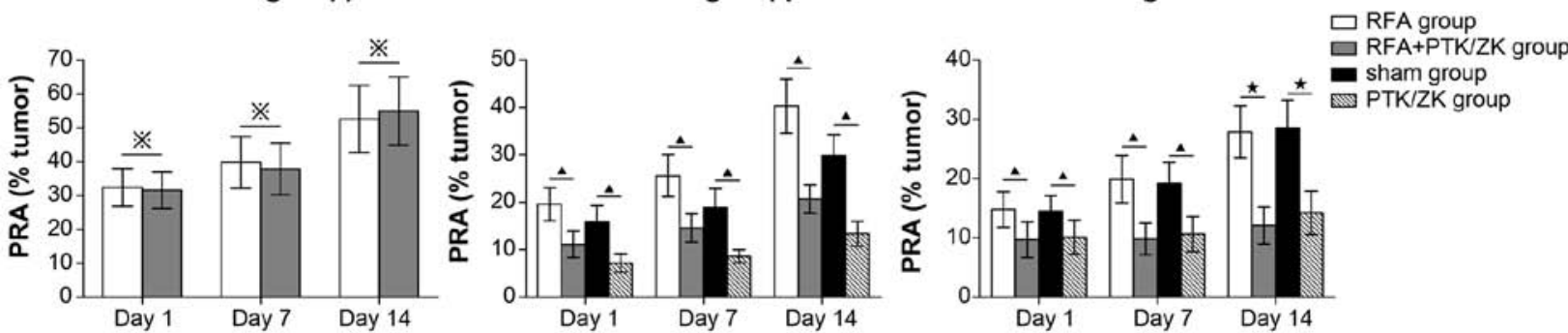

Figure 5. Angiogenesis potential is higher in the TZ than that in the RZ of the RUL and RLL, but has no effect on tumor proliferation. (A-C) Immunostaining showed CD34-positive staining in the TZ (A), RZ in RUL (B) and RZ in RLL (C) of the RFA group and RFA + YC-1 group. (D) Based on the semi-quantitative analysis of the CD34-positive stained area, it was noted that the MVD value of the TZ was higher than that of the RZ in the RUL and RLL at day 1,7 and 14 following RFA treatment, but when treated with YC-1, MVD values of the TZ, RZ in RUL and RLL were decreased. "P<0.01, RFA group vs. RFA + YC-1 group in TZ, RZ in RUL and RZ in RLL; ${ }^{* *} \mathrm{P}<0.05$, RFA group: TZ vs. RZ in RUL; ${ }^{* * * *} \mathrm{P}<0.05$, RFA group: TZ vs. RZ in RLL. (E) The effect of PTK/ZK on perilesional outgrowth of established micrometastases evaluated 1, 7 and 14 days. After RFA treatment, tumor growth was expressed as the PRA in the TZ and RZ. In the RFA and sham groups, treatment with PTK/ZK reduced tumor growth in the RZ of the RUL and RLL. *p $>0.05$, RFA group vs. RFA + PTK/ ZK group; ${ }^{\wedge} \mathrm{p}<0.05$, RFA group vs. RFA + PTK/ZK group or sham group vs. PTK/ZK group; ${ }^{\star} \mathrm{P}<0.01, \mathrm{RFA}$ group vs. RFA + PTK/ZK group or sham group vs. PTK/ZK group.

associated with an increased rate of local recurrence, which emphasizes the importance of obtaining satisfactory ablative margins (23). However, even when complete tumor destruction is achieved and satisfactory ablation margins have been created, residual tumor cells could survive in the transition zone (TZ) between the necrosis induced by RFA and the normal tissue (24). Therefore, a new opinion was put forward that the biological characteristics of the microenvironment in the $\mathrm{TZ}$ are critically important in the timing and prognosis of tumor local recurrences (25). Stoeckelhuber et al proposed that a clear demarcation between the ablation zones and TZs should be the criterion used to judge the success of RFA treatment. Applicable parameters of RFA, such as ablation temperature, time and the depth of needle-electrode puncture were selected as sentinels according to the results of immunohistochemisty and hematoxylin and eosin (H\&E) staining. The parameters of RFA that result in the maximum diameter of the ablation zone and the maximum width of the TZ were selected for treatment (26). Thermal destruction therapies will unequivocally produce a $\mathrm{TZ}$, such that the growth of residual tumor cells that are located in the TZ may be accelerated and cause local recurrences (27). 
Table IV. MVD $\left(\mathrm{mm}^{2}\right)$ in TZ and RZ at days 1, 7 and 14 following RFA.

$\mathrm{A}, \mathrm{MVD}\left(\mathrm{mm}^{2}\right)$ in TZ and RZ at day 1 following RFA

\begin{tabular}{|c|c|c|c|c|}
\hline Group & $\mathrm{TZ}$ & RZ in RUL & RZ in RLL & P-value \\
\hline RFA & $156.7 \pm 30.99$ & $127.8 \pm 24.34$ & $119.8 \pm 19.9$ & $\begin{array}{l}\text { TZ: } p=0.000 \text { RFA group vs. RFA + YC-1 group } \\
\text { RZ in RUL: } p=0.004 \text { RFA group vs. RFA + YC-1 group } \\
\text { RZ in RLL: } p=0.000 \text { RFA group vs. RFA + YC- } 1 \text { group }\end{array}$ \\
\hline $\mathrm{RFA}+\mathrm{YC}-1$ & $82.2 \pm 20.67$ & $43.1 \pm 8.65$ & $37.8 \pm 7.12$ & $\begin{array}{l}\mathrm{p}=0.047 \text { RFA group: } \mathrm{TZ} \text { vs. } \mathrm{RZ} \text { in RLL } \\
\mathrm{p}=0.025 \text { RFA group: } \mathrm{TZ} \text { vs. } \mathrm{RZ} \text { in RUL }\end{array}$ \\
\hline
\end{tabular}

$\mathrm{B}, \mathrm{MVD}\left(\mathrm{mm}^{2}\right)$ in TZ and RZ at day 7 following RFA

\begin{tabular}{lccll}
\hline Group & TZ & RZ in RUL & RZ in RLL & \\
\hline RFA & $121.3 \pm 32.3$ & $89.6 \pm 21.1$ & $83.7 \pm 19.8$ & $\begin{array}{l}\text { TZ: } \mathrm{p}=0.000 \text { RFA group vs. RFA + YC-1 group } \\
\text { RZ in RUL: } \mathrm{p}=0.000 \text { RFA group vs. RFA + YC-1 group } \\
\end{array}$ \\
& & & $\begin{array}{l}\text { RZ in RLL: } \mathrm{p}=0.000 \text { RFA group vs. RFA + YC-1 group } \\
\mathrm{p}=0.017 \text { RFA group: TZ vs. RZ in RLL } \\
\text { p }=0.020 \text { RFA group: TZ vs. RZ in RUL }\end{array}$
\end{tabular}

C, MVD $\left(\mathrm{mm}^{2}\right)$ in TZ and RZ at day 14 following RFA

\begin{tabular}{|c|c|c|c|c|}
\hline Group & $\mathrm{TZ}$ & RZ in RUL & RZ in RLL & P-value \\
\hline RFA & $94.1 \pm 22.3$ & $76.5 \pm 21.5$ & $74.3 \pm 19.8$ & $\begin{array}{l}\text { TZ: } p=0.008 \text { RFA group vs. RFA }+Y C-1 \text { group } \\
\text { RZ in RUL: } p=0.000 \text { RFA group vs. RFA }+Y C-1 \text { group } \\
\text { RZ in RLL: } p=0.001 \text { RFA group vs. RFA }+Y C-1 \text { group }\end{array}$ \\
\hline $\mathrm{RFA}+\mathrm{YC}-1$ & $43.1 \pm 12.14$ & $21.6 \pm 8.32$ & $24.7 \pm 7.63$ & $\begin{array}{l}\mathrm{p}=0.044 \text { RFA group: } \mathrm{TZ} \text { vs. } \mathrm{RZ} \text { in RLL } \\
\mathrm{p}=0.049 \text { RFA group: } \mathrm{TZ} \text { vs. RZ in RUL }\end{array}$ \\
\hline
\end{tabular}

MVD, microvessel density; TZ, transition zone; RZ, reference zones; RFA, radiofrequency ablation; RUL, right upper lobe; RLL, right lower lobe.

In general, hyperthermia can directly inhibit the proliferation of tumor cells $(28,29)$, while the tumor cells surviving in the TZ following RFA may overproliferate. There are two factors that may account for this phenomenon. First, hyperthermia treatment creates a local hypoxic microenvironment, which is often observed in the TZ surrounding the necrosis zone. Nikfarjam et al (33) found that following RFA treatment of liver metastases, a highly localized hypoxia-driven acceleration of tumor growth occurs in the TZ. However, angiogenesis is not the driving force behind RFA-stimulated tumor growth, indicating that other hypoxia-activated pathways are likely important (16). HIF-1 $\alpha$ is a master regulator of the essential adaptive responses to hypoxia, which is highly expressed under hypoxic conditions and is maintained at a constant low concentration under normoxic condition (30).

In the present study, HIF-1 $\alpha$ immunostaining was mainly localized immediately adjacent to the necrotic area, and strong HIF-1 $\alpha$ staining was observed in tumor cells or the extracellular matrix of the TZ following RFA. After treatment with a specific inhibitor of HIF-1 $\alpha$ (YC-1), HIF-1 $\alpha$ expression in the TZ decreased, while the angiogenesis potential was also significantly reduced. Angiogenesis potential is critical to tumor proliferation (31), as indicated by the results of our previous studies in SCLC cells (14). HIF-1 $\alpha$ promotes angiogenesis potential by upregulating VEGF-A expression. VEGF-A is one of the best-studied downstream effectors of HIF- $1 \alpha$, and it plays a pivotal role in the stimulation of hypoxia-driven angiogenesis (32). Several angiogenic factors, including VEGF-A, are upregulated primarily adjacent to the ablation zone (33). PTK787/ZK-222584, a specific inhibitor that reduces VEGF-A expression, has been widely used in the clinical treatment of SCLCs (34). However, in the present study, while PTK/ZK largely inhibited the angiogenic response, it had no significant effect on tumor proliferation in the TZ, in sharp contrast to $\mathrm{YC}-1$, which reduced proliferation. For this reason, RFA is an important method for tumor hyperthermia and can destroy tumor cells by generating high temperatures. Heat shock proteins (HSPs), synthesized under heat stress, can facilitate recovery of tumor cells from heat damage (35). For example, HSP90 expression is upregulated in response to stresses such as hypoxia and hyperthermia, followed by modulation of numerous targets aimed at promoting cell 
Table V. PRA value (\%) in TZ, in RZ of RUL and in RZ of RLL at days 1, 7 and 14.

A, PRA value $(\%)$ in $\mathrm{TZ}$

\begin{tabular}{|c|c|c|c|c|}
\hline Group & Day 1 & Day 7 & Day 14 & P-value \\
\hline RFA & $32.4 \pm 5.62$ & $39.8 \pm 7.62$ & $52.6 \pm 9.89$ & $\begin{array}{l}\text { Day 1: } p=0.079 \text { RFA group vs. RFA }+Y C-1 \text { group } \\
\text { Day 7: } p=0.088 \text { RFA group vs. RFA }+Y C-1 \text { group }\end{array}$ \\
\hline $\mathrm{RFA}+\mathrm{PTK} / \mathrm{ZK}$ & $31.6 \pm 5.37$ & $37.9 \pm 7.64$ & $54.5 \pm 10.1$ & Day 14: $\mathrm{p}=0.091$ RFA group vs. RFA + YC-1 group \\
\hline
\end{tabular}

$\mathrm{B}, \mathrm{PRA}$ value $(\%)$ in RZ of RUL

\begin{tabular}{lrrll}
\hline Group & Day 1 & Day 7 & Day 14 & \\
\hline RFA & $19.6 \pm 3.46$ & $25.6 \pm 4.42$ & $40.3 \pm 5.69$ & Compared with RFA group and RFA + PTK/ZK group; \\
RFA + PTK/ZK & $11.1 \pm 2.79$ & $14.6 \pm 2.98$ & $20.7 \pm 3.01$ & Day 1: $\mathrm{p}=0.028$, day 7: $\mathrm{p}=0.021$, day $14: \mathrm{p}=0.014$ \\
Sham & $15.9 \pm 3.43$ & $18.9 \pm 3.99$ & $29.8 \pm 4.53$ & Compared with sham group and PTK/ZK group; \\
PTK/ZK & $7.2 \pm 1.96$ & $8.6 \pm 1.37$ & $13.4 \pm 2.64$ & Day 1: $\mathrm{p}=0.037$, day $7: \mathrm{p}=0.025$, day $14: \mathrm{p}=0.017$ \\
\hline
\end{tabular}

C, PRA value (\%) in RZ of RLL

\begin{tabular}{lrrll}
\hline Group & \multicolumn{1}{c}{ Day 1 } & \multicolumn{1}{c}{ Day 7} & Day 14 & P-value \\
\hline RFA & $14.8 \pm 2.98$ & $19.9 \pm 3.98$ & $27.9 \pm 4.39$ & Compared with RFA group and RFA + PTK/ZK group; \\
RFA + PTK/ZK & $9.6 \pm 3.01$ & $9.8 \pm 2.65$ & $12.1 \pm 3.12$ & Day 1: $\mathrm{p}=0.038$, day 7: $\mathrm{p}=0.017$, day 14: $\mathrm{p}=0.009$ \\
Sham & $14.5 \pm 2.62$ & $19.2 \pm 3.52$ & $28.5 \pm 4.74$ & Compared with sham group and PTK/ZK group; \\
PTK/ZK & $10.1 \pm 2.89$ & $10.6 \pm 2.95$ & $14.2 \pm 3.67$ & Day 1: $\mathrm{p}=0.047$, day 7: $\mathrm{p}=0.015$, day $14: \mathrm{p}=0.007$ \\
\hline
\end{tabular}

TZ, transition zone; RZ, reference zones; RFA, radiofrequency ablation; RUL, right upper lobe; RLL, right lower lobe.

survival, including HIF-1 $\alpha$ (36). HSP70 plays an important role in protecting cell death from a variety of stresses and the upregulation of inducible HSP70 expression can stabilize HIF-1 $\alpha$ expression through p $85 \alpha$ mediation (37). Thus, it is speculated that upregulation of expression of HIF-1 $\alpha$ in TZ and RZ of RUL may be induced by HSPs (HSP90 or HSP70) following RFA treatment. VEGF is one of the best studied downstream effectors of HIF and plays a pivotal role in the stimulation of hypoxia-driven angiogenesis (14), Meanwhile, HSP70-HSP90 heat shock protein can also stimulate degradation of endothelial VEGFR and inhibit the angiogenesis of tumors (38). Therefore, we believe that the angiogenesis in TZ is regulated to a great extent by HSP and cannot independently affect the growth of tumors in the TZ. Thus, inhibition of angiogenesis in the TZ following RFA treatment had no significant effect on the overproliferation of residual SCLC cells. Hence, HSPs/HIF-1 $\alpha$ may play a vital role in regulating the proliferation rate of residual SCLC cells in $\mathrm{TZ}$ and the underlying specific molecular mechanism involved in the regulation of HIF-1 $\alpha$ expression by HSPs will be investigated in our future study.

RFA has been proposed as an acceptable alternative for the treatment of SCLCs. Although this technique and the conditions of ablation have been improved by applying multipolar ablation or widening the ablation margin, local recurrence is still common. Multidisciplinary synthetic therapy, which is RFA combined with another treatment has subsequently gained appeal. Recently, adjuvant treatments used in combination with thermal destruction therapies such as RFA have mainly involved the addition of cytotoxic agents (39). In preclinical tests, the combination of RFA with doxorubicin-based chemotherapy created an increase in coagulation size and reduced the risk of recurrence (40). As accelerated overproliferation (elicited by RFA) was associated with hypoxia in our study, hypoxia-activated prodrugs may be efficacious in the adjuvant treatment of SCLC following RFA. Molecular-targeted therapy against HIF-1 $\alpha$ may also prove to be a suitable adjuvant treatment for RFA. In addition, hyperthermia may elicit an antitumor $\mathrm{T}$ cell response by presenting tumor antigens to the immune system, ultimately resulting in the inhibition of tumor proliferation (41). Our future study will focus on developing methods to induce an antitumor immune response. Our study provides a theoretical basis for the development of new multidisciplinary synthetic therapies for SCLCs typically treated with RFA alone.

\section{Acknowledgements}

The present study was funded by the National Nature Science Foundation of China (no. 81302028). The authors would like to thank the Duoease Scientific Service Center for excellent language editing service and suggestions for Figure revision. 


\section{References}

1. Varela G and Thomas PA: Surgical management of advanced non-small cell lung cancer. J Thorac Dis 6 (Suppl 2): S217-S223, 2014.

2. Schreiner W, Semrau S, Fietkau R and Sirbu H: Oligometastatic non-small cell lung cancer - surgical options and therapy strategies. Zentralbl Chir 139: 335-341, 2014 (In German).

3. Bolca C, Dănăilă O, Paleru C and Cordoş I: Role of surgery in small cell lung cancer. Pneumologia 62: 236-238, 2013 (In Romanian)

4. Hosono MN, Hosono M, Endo K, Ueda R and Onoyama Y: Effect of hyperthermia on tumor uptake of radiolabeled anti-neural cell adhesion molecule antibody in small-cell lung cancer xenografts J Nucl Med 35: 504-509, 1994

5. Kawahara T, Ito H, Terao H, Kato Y, Uemura H, Kubota Y and Matsuzaki J: Effectiveness of ureteroscopy-assisted retrograde nephrostomy (UARN) for percutaneous nephrolithotomy (PCNL). PLoS One 7: e52149, 2012.

6. Alexander ES and Dupuy DE: Lung cancer ablation: Technologies and techniques. Semin Intervent Radiol 30: 141-150, 2013.

7. Roberton BJ, Liu D, Power M, Wan JM, Stuart S, Klass D and Yee J: Pulmonary ablation: A primer. Can Assoc Radiol J 65: 177-185, 2014.

8. Lanuti M, Sharma A, Willers H, Digumarthy SR, Mathisen DJ and Shepard JA: Radiofrequency ablation for stage I non-small cell lung cancer: Management of locoregional recurrence. Ann Thorac Surg 93: 921-927, discussion 927-988, 2012.

9. Goldberg SN, Gazelle GS, Compton CC, Mueller PR and Tanabe KK: Treatment of intrahepatic malignancy with radiofrequency ablation: Radiologic-pathologic correlation. Cancer 88 : 2452-2463, 2000.

10. Yamada S, Utsunomiya T, Morine $\mathrm{Y}$, Imura S, Ikemoto $\mathrm{T}$, Arakawa Y, Kanamoto M, Iwahashi S, Saito Y, Takasu C, et al: Expressions of hypoxia-inducible factor-1 and epithelial cell adhesion molecule are linked with aggressive local recurrence of hepatocellular carcinoma after radiofrequency ablation therapy. Ann Surg Oncol 21 (Suppl 3): S436-S442, 2014.

11. Beland MD, Wasser EJ, Mayo-Smith WW and Dupuy DE: Primary non-small cell lung cancer: Review of frequency, location, and time of recurrence after radiofrequency ablation. Radiology 254: 301-307, 2010.

12. Fraga A, Ribeiro R and Medeiros R: Tumor hypoxia: The role of HIF. Actas Urol Esp 33: 941-951, 2009 (In Spanish).

13. Wan J, Ma J, Mei J and Shan G: The effects of HIF-1alpha on gene expression profiles of NCI-H446 human small cell lung cancer cells. J Exp Clin Cancer Res 28: 150, 2009.

14. Wan J, Chai H, Yu Z, Ge W, Kang N, Xia W and Che Y: HIF-1 $\alpha$ effects on angiogenic potential in human small cell lung carcinoma. J Exp Clin Cancer Res 30: 77, 2011.

15. Tsui L, Fong TH and Wang IJ: YC-1 targeting of hypoxiainducible factor- $1 \alpha$ reduces RGC-5 cell viability and inhibits cell proliferation. Mol Vis 18: 1594-1603, 2012.

16. Nijkamp MW, van der Bilt JD, de Bruijn MT, Molenaar IQ, Voest EE, van Diest PJ, Kranenburg O and Borel Rinkes IH: Accelerated perinecrotic outgrowth of colorectal liver metastases following radiofrequency ablation is a hypoxia-driven phenomenon. Ann Surg 249: 814-823, 2009.

17. Holleran JL, Miller CJ, Edgehouse NL, Pretlow TP and Culp LA: Differential experimental micrometastasis to lung, liver, and bone with lacZ-tagged CWR22R prostate carcinoma cells. Clin Exp Metastasis 19: 17-24, 2002.

18. Bott MJ and Crabtree T: Treatment of stage I lung cancer in high-risk and inoperable patients: SBRT vs. RFA vs. sublobar resection. Ann Cardiothorac Surg 3: 167-169, 2014.

19. Baisi A, Raveglia F, De Simone M and Cioffi U: Palliative role of percutaneous radiofrequency ablation for severe hemoptysis in an elderly patient with inoperable lung cancer. J Thorac Cardiovasc Surg 140: 1196-1197, 2010.

20. Kelekis AD, Thanos L, Mylona S, Ptohis N, Malagari K, Nikita A, Christodoulidou $\mathrm{J}$ and Kelekis N: Percutaneous radiofrequency ablation of lung tumors with expandable needle electrodes: Current status. Eur Radiol 16: 2471-2482, 2006.

21. Kashima M, Yamakado K, Takaki H, Kodama H, Yamada T, Uraki J and Nakatsuka A: Complications after 1000 lung radiofrequency ablation sessions in 420 patients: A single center's experiences. AJR Am J Roentgenol 197: W576-W580, 2011.

22. Baisi A, Raveglia F, De Simone $M$ and Cioffi U: Recurrence after radiofrequency ablation for stage I non-small cell lung cancer. Ann Thorac Surg 94: 1788-1789, 2012.
23. Mulier S, Ni Y, Jamart J, Ruers T, Marchal G and Michel L: Local recurrence after hepatic radiofrequency coagulation: Multivariate meta-analysis and review of contributing factors. Ann Surg 242: 158-171, 2005.

24. Nijkamp MW, Borren A, Govaert KM, Hoogwater FJ, Molenaar IQ, van Diest PJ, Kranenburg O and Borel Rinkes IH: Radiofrequency ablation of colorectal liver metastases induces an inflammatory response in distant hepatic metastases but not in local accelerated outgrowth. J Surg Oncol 101: 551-556, 2010.

25. Okhunov Z, Roy O, Duty B, Waingankar N, Herati A Morgenstern N, Sheikh-Fayyaz S and Kavoussi LR: Clinical evaluation of a novel bipolar radiofrequency ablation system for renal masses. BJU Int 110: 688-691, 2012.

26. Stoeckelhuber BM, Noack F, Kapsimalakou S, Rudolf I, Bergmann-Koester CU, Helmberger T and Stoeckelhuber M: Radiofrequency ablation in breast tissue: Experimental study for evaluation of radiofrequency effects in the bovine udder and review of the literature. J Vasc Interv Radiol 20: 1477-1482, 2009.

27. Frich L, Bjørnland K, Pettersen S, Clausen OP and Gladhaug IP Increased activity of matrix metalloproteinase 2 and 9 after hepatic radiofrequency ablation. J Surg Res 135: 297-304, 2006.

28. Takagi H, Azuma K, Tsuka T, Imagawa T, Osaki T and Okamoto Y: Antitumor effects of high-temperature hyperthermia on a glioma rat model. Oncol Lett 7: 1007-1010, 2014.

29. Chen EY, Samkoe KS, Hodge S, Tai K, Hou H, Petryk AA, Strawbridge R, Hoopes PJ and Khan N: Modulation of hypoxia by magnetic nanoparticle hyperthermia to augment therapeutic index. Adv Exp Med Biol 812: 87-95, 2014.

30. Brocato J, Chervona Y and Costa M: Molecular responses to hypoxia-inducible factor $1 \alpha$ and beyond. Mol Pharmacol 85: 651-657, 2014.

31. Mittal K, Ebos J and Rini B: Angiogenesis and the tumor microenvironment: Vascular endothelial growth factor and beyond. Semin Oncol 41: 235-251, 2014.

32. Shahneh FZ, Baradaran B, Zamani F and Aghebati-Maleki L: Tumor angiogenesis and anti-angiogenic therapies. Hum Antibodies 22: 15-19, 2013.

33. Nikfarjam M, Muralidharan V and Christophi C: Altered growth patterns of colorectal liver metastases after thermal ablation. Surgery 139: 73-81, 2006.

34. Pati S, Orsi SA, Moore AN and Dash PK: Intra-hippocampal administration of the VEGF receptor blocker PTK787/ZK222584 impairs long-term memory. Brain Res 1256: 85-91, 2009.

35. Selvarajah GT, Bonestroo FA, Kirpensteijn J, Kik MJ, van der Zee R, van Eden W, Timmermans-Sprang EP, Slob A and Mol JA: Heat shock protein expression analysis in canine osteosarcoma reveals HSP60 as a potentially relevant therapeutic target. Cell Stress Chaperones 18: 607-622, 2013.

36. Katschinski DM, Le L, Heinrich D, Wagner KF, Hofer T, Schindler SG and Wenger RH: Heat induction of the unphosphorylated form of hypoxia-inducible factor-1alpha is dependent on heat shock protein-90 activity. J Biol Chem 277: 9262-9267, 2002.

37. Guo W, Yang Z, Xia Q, Liu J, Yu Y, Li J, Zuo Z, Zhang D, Li X, Shi X, et al: Arsenite stabilizes HIF-1 $\alpha$ protein through $\mathrm{p} 85 \alpha-$ mediated up-regulation of inducible Hsp70 protein expression. Cell Mol Life Sci 68: 475-488, 2011.

38. Bruns AF, Yuldasheva N, Latham AM, Bao L, Pellet-Many C Frankel P, Stephen SL, Howell GJ, Wheatcroft SB, Kearney MT, et al: A heat-shock protein axis regulates VEGFR2 proteolysis, blood vessel development and repair. PLoS One 7: e48539, 2012.

39. Ahmed M, Liu Z, Lukyanov AN, Signoretti S, Horkan C, Monsky WL, Torchilin VP and Goldberg SN: Combination radiofrequency ablation with intratumoral liposomal doxorubicin: Effect on drug accumulation and coagulation in multiple tissues and tumor types in animals. Radiology 235: 469-477, 2005.

40. Veenendaal LM, van Hillegersberg $\mathrm{R}$, Smakman $\mathrm{N}$ van der Bilt JD, van Diest PJ, Kranenburg O and Borel Rinkes IH: Synergistic effect of interstitial laser coagulation and doxorubicin in a murine tumor recurrence model of solitary colorectal liver metastasis. Ann Surg Oncol 13: 168-175, 2006.

41. Isbert C, Ritz JP, Roggan A, Schuppan D, Rühl M, Buhr HJ and Germer CT: Enhancement of the immune response to residual intrahepatic tumor tissue by laser-induced thermotherapy (LITT) compared to hepatic resection. Lasers Surg Med 35: 284-292, 2004. 